\title{
Advances in the mechanisms of action of cancer-targeting oncolytic viruses (Review)
}

\author{
CUN-ZHI LIN $^{1 *}$, GUI-LING XIANG $^{1 *}$, XIN-HONG ZHU ${ }^{2}$, LU-LU XIU $^{1}$, JIA-XING SUN ${ }^{1}$ and XIAO-YUAN ZHANG ${ }^{1}$ \\ ${ }^{1}$ Department of Respiratory Medicine, The Affiliated Hospital of Qingdao University, Qingdao, Shandong 266003; \\ ${ }^{2}$ Department of General Medicine, Qingdao Municipal Hospital, Qingdao, Shandong 266071, P.R. China
}

Received February 3, 2017; Accepted November 30, 2017

DOI: $10.3892 / \mathrm{ol} .2018 .7829$

\begin{abstract}
Cancer virotherapy mediated by oncolytic viruses (OV), has emerged as a novel and effective strategy in cancer therapeutics. Preclinical models have demonstrated anticancer activity against numerous types of cancer. Currently, a number of recombinant viruses are in late phase clinical trials, many of which have demonstrated promising results regarding the safety and reliability of the treatments, particularly when combined with standard antineoplastic therapies. In addition to molecular-targeted therapeutics, genetic engineering of the viruses allows functional complementation to chemotherapy or radiotherapy agents. Co-administration of chemotherapy or radiotherapy is imperative for an effective treatment regime. Additionally, these approaches may be used in combination with current treatments to assist in cancer management. The near future may reveal whether this renewed interest in oncological virotherapy will result in meaningful therapeutic effects in patients. The aim of the present review was to highlight how the knowledge of oncolytic viral specificity and cytotoxicity has advanced in recent years, with a view to discuss OV in clinical application and the future directions of this field.
\end{abstract}

\section{Contents}

1. Introduction

2. Specificity of OV in succumbing tumor cells

3. Lethal effect of $\mathrm{OV}$ on tumor cells

Correspondence to: Professor Xin-Hong Zhu, Department of General Medicine, Qingdao Municipal Hospital, 5 Donghai Middle Road, Qingdao, Shandong 266071, P.R. China

E-mail: zhudoc@126.com

*Contributed equally

Abbreviations: OV, oncolytic viruses; uPAR, urokinase receptor; GM-CSF, granulocyte-macrophage colony stimulating factor; OAd, oncolytic adenovirus

Key words: oncolytic virus, neoplasms, gene targeting, research, therapy
4. New trends in OV based approaches

5. Conclusions

\section{Introduction}

Oncolytic virotherapy is not a new concept; this area of research first arose as an observational science in the early 20 th century, when it was occasionally reported that cancer regression occurred spontaneously in patients following certain viral infections (1). Numerous experiments were carried out following these reports; however, the topic of anticancer viral therapy languished, due to the deficiency of specificity and the harmful side effects, as well as the limited knowledge regarding the mechanisms of how cancer cells succumb to oncolytic viruses (OVs) (2). Since the 1990s, the genomes of wild-type viruses have been selectively engineered as a result of the development of molecular virology; this has reignited interest in the use of replicating viruses as cancer therapeutics. The manufactured viruses are capable of preferential replication and proliferation in cancerous cells, which may cause the cancerous cells to die at the end of replication cycles via lysis or the activation of an antitumor immune response, with minimal damage to normal cells (3). Several OVs have been tested in humans, and although the safety results were optimistic, their efficacy as single agents was limited (4). Administration of chemotherapy or radiotherapy in addition to the viruses is vital for creating an effective treatment. Over the past two decades, the study of oncolytic virotherapy has grown exponentially alongside the advancement of molecular biology, virology, immunology and, particularly, genetic engineering (5). In addition, combinations with other treatment options, particularly cancer gene therapy, has been demonstrated the potential to strengthen the antitumor efficacy through viral amplification of the therapeutic transgene inside tumor cells and tissues (6). Various cancer-targeted OVs carry a number of exogenous genes that have transitioned from preclinical studies into early phase clinical testing and more recently into randomized clinical trials (Table I) (1). These include vaccinia, adenovirus, herpes simplex virus, reovirus and Newcastle disease virus $(7,8)$; additionally, novel OV species are being explored. The current status of clinical trials for such therapeutic OVs has recently been reviewed by Russell et al (9). 
Compared with conventional treatments for cancer, including chemotherapy and radiotherapy, the engineered OV strain expressing transgenes exhibits a contrasting mechanism of action, specificity and cross-resistance, among other characteristics (Fig. 1) (10-12).

\section{Specificity of $\mathrm{OV}$ in succumbing tumor cells}

The progression of a tumor is generally considered a stochastic, dynamic process; genetic and epigenetic changes are also involved, including in the limitless proliferative potential, evasion of apoptosis, enhanced angiogenic capacity, tissue invasion and metastasis, and modification of the intracellular signaling pathway. These changes may make malignant cells susceptible to an infection, due to a number of the pathways subverted by the tumor also being necessary for efficient antiviral responses. Once a virus penetrates into a tumor cell, the tumor microenvironment provides abundant support for viral replication; therefore, these changes create the conditions required for oncolytic viral selective replication in cancer cells $(11,12)$. The oncolytic viral targeting mechanism is divided into the following categories: Targeting transduction, targeting transcription, targeting translation and targeting pro-apoptosis mechanisms.

Targeting transduction. Tumor cells have specific and high surface expression of the oncolytic viral primary receptor, which is capable of binding to viral surface proteins via the receptor-ligand pathway, essential for transduction. The first step is absorption, followed by the viral surface adhesion protein combining with the target cell surface receptor, which initiates endocytic signaling pathways (13). A number of viruses have a natural tropism for tumor cells. This principle is illustrated by the susceptibility of malignant glioma cells to poliovirus, depending on the presence of CD155 on glial neoplasms $(14,15)$. Alternatively, in order to infect the targeted tumor cells, the viral surface binding protein, which has the ability to serve as a receptor, must transform by introducing a single chain antibody or a polypeptide binding ligand: For example, the urokinase receptor (UPAR) is overexpressed in multiple malignancies and serves a role in tumor invasion and angiogenesis $(16,17)$. Measles virus retargeted against human (MV-h-uPA) or mouse (MV-m-uPA) uPAR were constructed by superinducing the aminoterminal fragment of either human or mouse urokinase in the C-terminus of recombinant measles virus. In vitro experiments indicated that MV-h-uPA and MV-m-uPA were able to specifically infect cancer cells that overexpressed uPAR via the receptor-ligand pathway (18).

Targeting transcription. The approach to achieving tumor-selective viral replication has been to alter the function of the control of genetic transcription, which is essential in viral replication, to a tissue- or tumor-specific promoter. These promoters include human telomerase reverse transcription (hTERT) (19), hypoxia-inducible factor-1 (20), prostate-specific antigen (21) and $\alpha$-fetoprotein (22), among others. hTERT has been identified as a major protein that functions to maintain telomere length in tumors; however, it demonstrates little or no expression in normal cells, allowing cancer cells to subvert the Hayflick limit (23). An attenuated adenovirus 5 vector, OBP-301, was constructed, whereby the hTERT promoter element drives the expression of E1 genes: Due to only tumor cells with telomerase activity possessing the ability to activate this promoter, selective viral replication and oncolytic cell death was demonstrated (19).

In addition to this approach, a novel system, which may regulate oncolytic viral gene-targeted expression by exploiting microRNAs (miRNAs), has been developed. miRNAs are 20-22 nucleotides of small noncoding endogenously produced RNAs that can base pair to their target mRNAs. This enables them to guide post-transcriptional silencing of their target genes and determine the differential expression between cancerous and normal tissues (24). The negative regulation in gene expression makes it possible to utilize these miRNAs to inhibit viral replication in normal cells $(25,26)$. Aberrant expression of miRNAs has previously been observed in numerous types of cancer (27). The downregulation of miRNA (miR)-199 occurs consistently in almost all hepatocellular carcinomas (HCC), when compared with a normal liver (28). Additionally, a conditionally replication-competent oncolytic adenovirus (OAd), ad-199T, was generated by introducing miR-199 target sites within the 3'untranslated region of the E1A gene, essential for viral replication, in order that miR-199 demonstrated the capacity to negatively regulate E1A gene expression. As a result, ad-199T replication was inhibited in normal miR-199positive liver parenchyma, and unaffected in tumor cells with low expression of miR-199 (29).

Targeting translation. Type I interferons (IFNs), which are spontaneously produced in response to a viral infection, are an important cytokine (12). The mechanism of cancer evolution that causes the loss of antiviral responsiveness in the majority of cancer cell lines, particularly the activity of IFN-regulated signaling pathways, is not completely understood. Previous studies have revealed that tumor antiviral activity is incompatible with their own efficient cell growth, as IFN and IFN-responsive genes are known angiogenesis inhibitors (30), and are also recognized for their capacity to induce apoptosis (31). In addition, the deficiency of tumor antiviral activity renders it more susceptible to an infection compared with normal cells, which results in a survival advantage for viruses within tumor cells. The vesicular stomatitis virus (VSV) is sensitive to IFN and therefore has an advantage in cancer therapeutics, including using a defective IFN pathway, to preferentially infect and kill tumor cells (32). The targeting of cancer cells by the VSV can be improved by introducing mutations in the matrix $(\mathrm{M})$ protein. The M protein of VSV is a major structural protein that functions in virus assembly, as well as in the suppression of host gene expression, causing inhibition of IFNs and other antiviral proteins. The ability of the M protein to subdue host gene expression is genetically distinct from its viral assembly function. Furthermore, various mutations render the $\mathrm{M}$ protein defective in its ability to suppress host gene expression, without subverting its ability to function in viral assembly (33). As a result, normal cells, due to the activated IFN pathway, inhibit the M protein mutant VSV replication; otherwise cancer cells with defects in the IFN pathway are killed by M protein mutant VSV selective replication (34). 


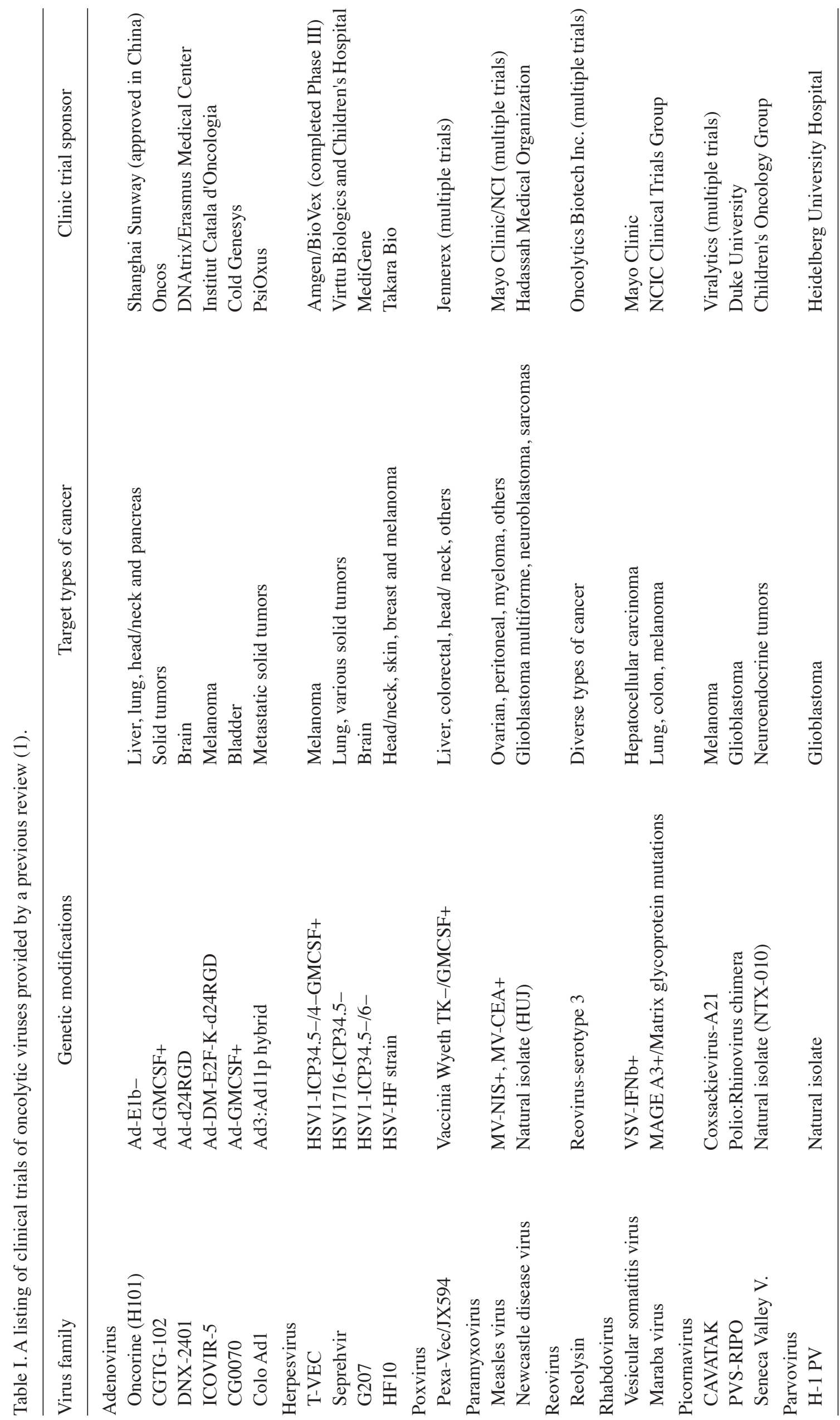




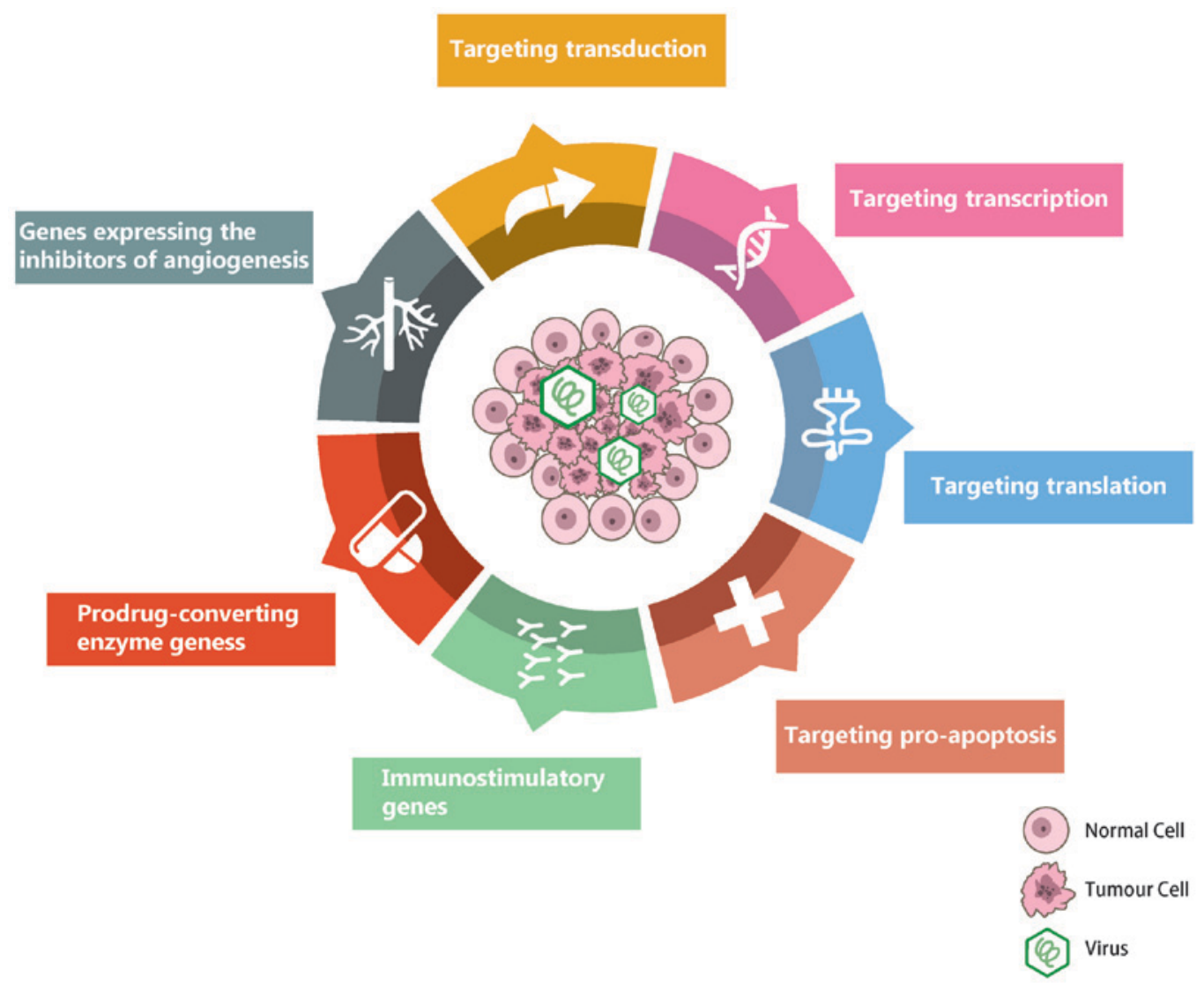

Figure 1. OV are designed to grow in the tumor niche. There are at least seven key action mechanisms that could be engineered or selected for OV specificity or cytotoxicity to tumor cells. OV, Oncolytic virus.

Targeting pro-apoptosismechanisms.TP53 serves a key function in inducing apoptosis by prompting cell cycle arrest, due to activation in response to oncogene activation, DNA damage and other stress signals (35). p53 is the most frequently mutated gene in cancer, being altered in $>50 \%$ of all types of human malignancies (36). The mutated $p 53$ gene is an important hallmark of cancer (37). Viruses have evolved the ability to inhibit the apoptosis of host cells, in order to accomplish viral replication. The E1B55K adenovirus codes for the protein that inactivates the p53 protein of host cells, contributing to self-proliferation and virus replication (38). China approved the world's first OV therapy for cancer treatment (39). OV, also termed H101, has been approved for the treatment of numerous types of cancer clinically (40), H101 is a type of OAd with E1B-55KD and partial E3 deletion, and it cannot replicate in normal cells where p53 is active; therefore, H101 can selectively infect and kill tumor cells via the targeting of pro-apoptosis $(41,42)$.

\section{Lethal effect of $\mathrm{OV}$ on tumor cells}

An important reason why OVs are currently being advanced as a promising antitumor modality is that they are able to transfer and amplify therapeutic genes, whilst simultaneously avoiding immunosurveillance by infected host cells (43). Virosomes are utilized as vectors for the delivery of toxic genes, including immunostimulatory genes [for instance, interleukin-12 (IL-12) (44)], anti-angiogenic genes (45), prodrug-converting enzyme genes and pro-apoptotic genes, to advance its potency, which can be used for oncotherapy (46).
Immunostimulatory genes. Delivery of immunostimulatory genes to cancer cells should boost immune responses against tumor antigens and the activity of cytotoxic effector cells, as a result of an abnormal increase of inflammatory infiltrates in the tumor milieu (47). Currently, a variety of immunostimulatory genes are used as part of recombinant oncolytic virusal vectors, which are utilized in viral gene therapy, including granulocyte-macrophage colony stimulating factor (GM-CSF) (48), IL-2, IL-12, IL-15 and IL-18 (49,50), IFN- $\alpha$ and IFN- $\beta$ (51,52). Previously, Choi et al (49) generated IL-12and IL-18-expressing (Ad- $\Delta$ E1Bmt7/IL-12/IL-18) OAd. IL-12 has been demonstrated to directly activate cytotoxic $\mathrm{T}$ cells and natural killer (NK) cells, which then produce high levels of IFN- $\gamma$, enhance their cytolytic activity and induce an antitumor effect (46); however, despite encouraging results in animal models, weaker antitumor effects of IL-12 were recorded in early clinical trials, and frequently accompanied by unacceptable levels of adverse events $(53,54)$. This markedly dampened the hopes of the clinical application of this cytokine in patients with cancer. In order to minimize the adverse events of an IL-12-based therapy, a decrease in the systemic expression of IL-12 has been the selected approach. This approach involves patients who are injected intratumorally with Ad-RTS-hIL-12, an adenoviral vector engineered for the controlled expression of IL-12. Preliminary results were encouraging, with positive clinical efficacy observed in $5 / 7$ patients treated with Ad-RTS-IL-12. These responses were associated with intratumoral IL-12 mRNA expression, reflected as a decrease in the size of the injected and distant lesions (55). IL-18 serves a 
function in inducing the differentiation of antitumor effector $\mathrm{T}$ cells and the activation of NK cells, which exhibit potent cytotoxicity against tumor cells (56). In a B16-F10 murine melanoma model, IL-12, IL-18, IFN- $\gamma$ and GM-CSF levels within the tumor tissues were significantly increased when treated with the intratumoral application of OAd co-expressing IL-12 and IL-18 compared with control virus-treated mice. Higher numbers of $\mathrm{CD}^{+} \mathrm{T}$ cells, $\mathrm{CD} 8^{+} \mathrm{T}$ cells and $\mathrm{NK}$ cells were detected via an immunohistochemical staining and the histological evaluation of tumor sections, which also exhibited large areas of necrosis compared with control virus-treated mice. These results further demonstrated the enhanced antitumor effects of OAd that express IL-12 and IL-18. The results were also validated in a murine colon adenocarcinoma model of MC38cea (48). IL-12- and IL-18-based immunotherapies were particularly efficacious in patients with cancer that contained inherited defects in IL-12 or IL-18 production, or with downregulated expression of IL-12 or IL-18. Compared with control virus-treated mice, the intratumoral administration of GM-CSF-expressing oncolytic MV markedly prolonged the median overall survival time (49).

Prodrug-converting enzyme genes. OVs were engineered to express prodrug-converting enzymes, which caused the conversion of the non-toxic prodrug into a toxic form, at the site of viral replication; therefore, causing selective tumor cell death. The prodrug-converting enzymes applied to the oncolytic virotherapy, including thymidine kinase (TK) (57), cytosine deaminase (CD) and purine-nucleoside phosphorylase (PNP) (58-60). The mechanism of action involves the conversion of the prodrug ganciclovir (GCV), via TK, into ganciclovir triphosphate (GCV-TP), CD converts the prodrug 5-fluorocytosine (5-FC) into 5-fluorouracil (5-FU) and PNP converts the prodrug fludarabine phosphate into 2-fluoroadenine. The transformed products are nucleoside analogs, which interfere with DNA replication in actively dividing tumor cells via the inhibition of DNA synthesis (61). A new recombinant herpes simplex virus type 1 thymidine kinase (HSV-1-TK), containing BoHV-4, has been constructed by Redaelli et al (62). The HSV-TK enzyme, which is an enzyme homologous to that of TK, has 1,000 times more affinity for the substrate GCV than the host cell TK (63). HSV-1-TK in combination with GCV has been identified as a promising suicide gene system, whereby GCV is phosphorylated by HSV-1-TK to form GCV-TP. GCV-TP has the ability to inhibit DNA polymerases, resulting from competing with deoxyguanosine triphosphate to bind to DNA polymerases, causing DNA damage that leads to cell death $(62,64)$. The active metabolite of TK, PNP and 5-FU can directly kill infected tumor cells. Furthermore, they promote a strong bystander effect on neighboring tumor cells that are not actively infected $(59,65,66)$. In a previous study by Leveille et al (67), recombinant vesicular stomatitis virus (VSV-MD51) expressing the cytosine deaminase/uracil phosphoribosyl-transferase suicide gene with the 5-FC prodrug was combined for the treatment of cancer. It was observed that there was a synergistic effect on killing cancer cells with VSV-MD51 and 5-FU in several cancer cell lines. The high solubility of $5-\mathrm{FU}$ is lethal to non-infected bystander tumor cells, which is an important advantage in using this combination.
Genes encoding the inhibitors of angiogenesis. In 1971, Folkman (68), to the best of our knowledge, first produced the hypothesis that tumor growth depends on angiogenesis, which also serves an essential role in tumor invasion and metastasis. Within four decades, anti-angiogenic therapy with broad targeting has rapidly evolved to become an integral component of current standard anticancer treatments $(69,70)$. Endostatin and angiostatin are two endogenous and broad-spectrum angiogenesis inhibitors. These inhibitors only function when they are continuously transported to the tumor microenvironment $(71,72)$. Additionally, it is difficult to make the two endogenous inhibitors function in the traditional way, due to characteristics of short serum half-lives, low solubility and poor stability $(73,74)$. Hutzen et al $(73)$ developed recombinant MVs that express human and mouse variants of endostatin: Angiostatin (E:A) fusion proteins, known as MV-hE:A and MV-mE:A, respectively. The in vitro study revealed that there is active MV replication and concomitant continuous expression of target genes within the medulloblastoma cells; therefore, angiogenic factors were inhibited, leading to a significant decrease in endothelial cell growth, viability and migration (73).

\section{New trends in OV based approaches}

Gene-based virotherapy mediated by OV is currently the focus of numerous studies; however, little attention has been given to the dual gene virotherapy strategy, which could be utilized as a novel therapeutic approach for mediating triplex anticancer combination effects, particularly if the two suitable genes are well selected (75). A number of the previously published reports have stated that a single therapeutic modality, including those mediated by tumor necrosis factor-associated apoptosis-inducing ligand (TRAIL) or IL-12 alone, could not achieve sufficient antitumor responses; therefore, combinations of anticancer therapeutics, including those mediated by dual gene-based cancer therapy, hold great promise for killing cancer cells in the future (76-78). The anticancer therapeutic potential of OAd virotherapy strategy-mediated co-delivery of TRAIL and IL-12 genes has not been sufficiently investigated thus far. El-Shemi et al (79) suggested in their preclinical study that dual therapy with Ad- $\Delta \mathrm{B} / \mathrm{TR}$ AIL plus Ad- $\Delta \mathrm{B} / \mathrm{IL}-12$ markedly suppressed human $\mathrm{HCC}$ via the promotion of antitumor apoptosis and immune activity, as well as by inhibiting tumor angiogenesis and neovascularization. Although further studies are warranted to evaluate this therapeutic combination, and also to explore the precise anti-tumor mechanisms, the OAd strategy-mediated co-delivery of TRAIL and IL-12 genes may be a potential therapeutic strategy for the treatment of human HCC, along with other types of cancer (79). Co-therapy with OAd-expressing TRAIL and another type of immunostimulant cytokine (IL-24) has been previously reported to be associated with potent activation in the caspase pathway, particularly of caspases-3 and -8, and apoptosis promotion in HCC (80). Comparatively, Han et al (81) demonstrated that treating patients with pancreatic cancer with gemcitabine and OAd armed with survivin shRNA and TRAIL greatly enhanced the cytotoxic death of pancreatic cancer cells (81). In addition, OVs utilized to simultaneously express dual anticancer genes have attracted an increased interest, as it has provided a 
multimodal method of killing cancer cells with an increased effectiveness, via a selective viral lytic effect on cancer cells and the additive or synergistic interaction between the two expressed anticancer genes $(82,83)$.

\section{Conclusions}

The oncolytic virotherapy area of study for cancer therapeutics has experienced considerable progress in recent years. Preclinical models have demonstrated an anticancer activity against numerous types of cancer (84). Currently, several recombinant viruses, including adenovirus, herpes simplex virus, vaccinia virus, reovirus, Newcastle disease virus and Parvovirus are in late phase clinical trials. A number of the clinical trials have indicated promising results, including in the safety and reliability of the treatment, particularly when combined with standard antineoplastic therapies (85). There is hope that oncolytic virotherapy will be included in the armamentarium of anticancer agents, and that certain groups of patients will benefit from the treatment. Despite the renewed hope, the following key challenges remain: OV cannot be viewed as a stand-alone therapy for any type of cancer; the safety of systemic administration remains untested; and the optimal arming strategies that combine chemo-, radio- and immuno-therapies require investigation (2). With the rapid development of molecular biology and cell biology techniques, cancer is viewed as a systemic and heterogeneous disease; therefore, using OV as a single therapy would be difficult when attempting to achieve the desired therapeutic effect. Individual and comprehensive therapies have become new trends in cancer therapy. Conventional therapies, including radiotherapy and chemotherapy, have various disadvantages, such as limited efficacy low specificity, cross-resistance, severe adverse effects and an eventual inability to meet the requirements of the patient (2). Oncolytic virotherapy as a new modality of cancer therapy is promising, and may be used to complement conventional therapies; however, the efficacy of combination therapy regimens must be validated. In the foreseeable future, an ever-growing number of recombinant OV may be used in clinical trials and applied in clinical practice.

\section{References}

1. Bell $\mathrm{J}$ and McFadden G: Viruses for tumor therapy. Cell Host Microbe 15: 260-265, 2014.

2. Fukuhara H, Ino $\mathrm{Y}$ and Todo T: Oncolytic virus therapy: A new era of cancer treatment at dawn. Cancer Sci 107: 1373-1379, 2016.

3. Liu TC, Galanis E and Kirn D: Clinical trial results with oncolytic virotherapy: A century of promise, a decade of progress. Nat Clin Pract Oncol 4: 101-117, 2007.

4. Nemunaitis J, Ganly I, Khuri F, Arseneau J, Kuhn J, McCarty T, Landers S, Maples P, Romel L, Randlev B, et al: Selective replication and oncolysis in p53 mutant tumors with ONYX-015, an E1B-55kD gene-deleted adenovirus, in patients with advanced head and neck cancer: A phase II trial. Cancer Res 60: 6359-6366, 2000.

5. Ruf B and Lauer UM: Assessment of current virotherapeutic application schemes: 'Hit hard and early' versus 'killing softly'? Mol Ther Oncolytics 4: 15018, 2015.

6. Breitbach CJ, Lichty BD and Bell JC: Oncolytic viruses: Therapeutics with an identity crisis. EBioMedicine 9: 31-36, 2016.

7. Cross D and Burmester JK: Gene therapy for cancer treatment: Past, present and future. Clini Med Res 4: 218-227, 2006.

8. Liu TC and Kirn D: Gene therapy progress and prospects cancer: Oncolytic viruses. Gene Ther 15: 877-884, 2008
9. Russell SJ, Peng KW and Bell JC: Oncolytic virotherapy. Nat Biotechnol 30: 658-670, 2012.

10. Galanis E, Atherton PJ, Maurer MJ, Knutson KL, Dowdy SC, Cliby WA, Haluska P Jr, Long HJ, Oberg A, Aderca I, et al: Oncolytic measles virus expressing the sodium iodide symporter to treat drug-resistant ovarian cancer. Cancer Res 75: 22-30, 2015.

11. Hanahan D and Weinberg RA: The hallmarks of cancer. Cell 100: $57-70,2000$.

12. Ilkow CS, Swift SL, Bell JC and Diallo JS: From scourge to cure: Tumour-selective viral pathogenesis as a new strategy against cancer. PLoS Pathog 10: e1003836, 2014.

13. Cattaneo R, Miest T, Shashkova EV and Barry MA: Reprogrammed viruses as cancer therapeutics: Targeted, armed and shielded. Nature Rev Microbiol 6: 529-540, 2008.

14. Gromeier M, Lachmann S, Rosenfeld MR, Gutin PH and Wimmer E: Intergeneric poliovirus recombinants for the treatment of malignant glioma. Proc Natl Acad Sci the USA 97: 6803-6808, 2000.

15. Merrill MK, Bernhardt G, Sampson JH, Wikstrand CJ, Bigner DD and Gromeier M: Poliovirus receptor CD155-targeted oncolysis of glioma. Neuro Oncol 6: 208-217, 2004.

16. Blasi F and Carmeliet P: uPAR: A versatile signalling orchestrator. Nat Rev Mol Cell Biol 3: 932-943, 2002.

17. Lester RD, Jo M, Montel V, Takimoto S and Gonias SL: uPAR induces epithelial-mesenchymal transition in hypoxic breast cancer cells. J Cell Biol 178: 425-436, 2007.

18. Jing Y, Zaias J, Duncan R, Russell SJ and Merchan JR: In vivo safety, biodistribution and antitumor effects of UPAR retargeted oncolytic measles virus in syngeneic cancer models. Gene Ther 21: 289-297, 2014.

19. Sato D, Kurihara Y, Kondo S, Shirota T, Urata Y, Fujiwara T and Shintani S: Antitumor effects of telomerase-specific replication-selective oncolytic viruses for adenoid cystic carcinoma cell lines. Oncol Rep 30: 2659-2664, 2013.

20. Longo SL, Griffith C, Glass A, Shillitoe EJ and Post DE: Development of an oncolytic herpes simplex virus using a tumor-specific HIF-responsive promoter. Cancer Gene Ther 18: 123-134, 2011.

21. Lu Y, Zhang Y, Chang G and Zhang J: Comparison of prostate-specific promoters and the use of PSP-driven virotherapy for prostate cancer. Biomed Res Int 2013: 624632, 2013.

22. Zhang KJ, Zhang J, Wu YM, Qian J, Liu XJ, Yan LC, Zhou XM, Xiao RJ, Wang YG, Cao X, et al: Complete eradication of hepatomas using an oncolytic adenovirus containing AFP promoter controlling E1A and an E1B deletion to drive IL-24 expression. Cancer Gene Ther 19: 619-629, 2012.

23. Verdun RE and Karlseder J: Replication and protection of telomeres. Nature 447: 924-931, 2007.

24. Giandomenico V, Thirlwell C and Essand M: Other Novel Therapies: Biomarkers, microRNAs and microRNA inhibitors, DNA methylation, epigenetics, immunotherapy and virotherapy. Front Horm Res 44: 248-262, 2015.

25. Ruiz AJ and Russell SJ: MicroRNAs and oncolytic viruses. Curr Opin Virol 13: 40-48, 2015.

26. Yao W, Guo G, Zhang Q, Fan L, Wu N and Bo Y: The application of multiple miRNA response elements enables oncolytic adenoviruses to possess specificity to glioma cells. Virology: 458-459: 69-82, 2014.

27. Negrini M, Ferracin M, Sabbioni S and Croce CM: MicroRNAs in human cancer: From research to therapy. J Cell Sci 120: 1833-1840, 2007.

28. Murakami Y, Yasuda T, Saigo K, Urashima T, Toyoda H, Okanoue $\mathrm{T}$ and Shimotohno K: Comprehensive analysis of microRNA expression patterns in hepatocellular carcinoma and non-tumorous tissues. Oncogene 25: 2537-2545, 2006.

29. Callegari E, Elamin BK, D'Abundo L, Falzoni S, Donvito G, Moshiri F, Milazzo M, Altavilla G, Giacomelli L, Fornari F, et al: Anti-tumor activity of a miR-199-dependent oncolytic adenovirus. PLoS One 8: e73964, 2013.

30. Indraccolo S: Interferon-alpha as angiogenesis inhibitor: Learning from tumor models. Autoimmunity 43: 244-247, 2010.

31. Kotredes KP and Gamero AM: Interferons as inducers of apoptosis in malignant cells. J Interferon Cytokine Res 33: 162-170, 2013.

32. Balachandran S and Barber GN: Vesicular stomatitis virus (VSV) therapy of tumors. IUBMB Life 50: 135-138, 2000.

33. Ahmed M, Cramer SD and Lyles DS: Sensitivity of prostate tumors to wild type and $\mathrm{M}$ protein mutant vesicular stomatitis viruses. Virology 330: 34-49, 2004. 
34. Stewart JH IV, Ahmed M, Northrup SA, Willingham M and Lyles DS: Vesicular stomatitis virus as a treatment for colorectal cancer. Cancer Gene Ther 18: 837-849, 2011.

35. Bradner JE: Cancer: An essential passenger with p53. Nature 520: 626-627, 2015.

36. Liu J, Zhang C and Feng Z: Tumor suppressor p53 and its gain-of-function mutants in cancer. Acta Biochim Biophys Sin (Shanghai) 46: 170-179, 2014.

37. Duffy MJ, Synnott NC, McGowan PM, Crown J, O'Connor D and Gallagher WM: p53 as a target for the treatment of cancer. Cancer Treat Rev 40: 1153-1160, 2014.

38. Bischoff JR, Kirn DH, Williams A, Heise C, Horn S, Muna M, Ng L, Nye JA, Sampson-Johannes A, Fattaey A and McCormick F: An adenovirus mutant that replicates selectively in p53-deficient human tumor cells. Science 274: 373-376, 1996.

39. Garber K: China approves world's first oncolytic virus therapy for cancer treatment. J Natl Cancer Inst 98: 298-300, 2006.

40. Cheng PH, Wechman SL, McMasters KM and Zhou HS: Oncolytic replication of E1b-Deleted adenoviruses. Viruses 7: $5767-5779,2015$

41. Song X, Zhou Y, Jia R, Xu X, Wang H, Hu J, Ge S and Fan X Inhibition of retinoblastoma in vitro and in vivo with conditionally replicating oncolytic adenovirus H101. Invest Ophthalmol Vis Sci 51: 2626-2635, 2010.

42. Yu W and Fang H: Clinical trials with oncolytic adenovirus in China. Curr Cancer Drug Targets 7: 141-148, 2007.

43. Kaneda Y: A non-replicating oncolytic vector as a novel therapeutic tool against cancer. BMB Rep 43: 773-780, 2010.

44. Gil-Farina I, Di Scala M, Vanrell L, Olagüe C, Vales A, High KA, Prieto J, Mingozzi F and Gonzalez-Aseguinolaza G: IL12-mediated liver inflammation reduces the formation of AAV transcriptionally active forms but has no effect over preexisting AAV transgene expression. PLoS One 8: e67748,2013.

45. Guse K, Sloniecka M, Diaconu I, Ottolino-Perry K, Tang N, $\mathrm{Ng} \mathrm{C}$, Le Boeuf F, Bell JC, McCart JA, Ristimäki A, et al: Antiangiogenic arming of an oncolytic vaccinia virus enhances antitumor efficacy in renal cell cancer models. J Virol 84: 856-866, 2010.

46. Jeyaretna DS and Kuroda T: Recent advances in the development of oncolytic HSV-1 vectors: 'Arming' of HSV-1 vectors and application of bacterial artificial chromosome technology for their construction. Curr Opin Mol Ther 9: 447-466, 2007.

47. Tsun A, Miao XN, Wang CM and Yu DC: Oncolytic immunotherapy for treatment of cancer. Adv Exp Med Biol 909: 241-283, 2016.

48. Grossardt C, Engeland CE, Bossow S, Halama N, Zaoui K, Leber MF, Springfeld C, Jaeger D, von Kalle C and Ungerechts G: Granulocyte-macrophage colony-stimulating factor-armed oncolytic measles virus is an effective therapeutic cancer vaccine. Hum Gene Ther 24: 644-654, 2013.

49. Choi IK, Lee JS, Zhang SN, Park J, Sonn CH, Lee KM and Yun CO: Oncolytic adenovirus co-expressing IL-12 and IL-18 improves tumor-specific immunity via differentiation of T cells expressing IL-12R $\beta 2$ or IL-18R $\alpha$. Gene Ther 18: 898-909, 2011.

50. van Rikxoort M, Michaelis M, Wolschek M, Muster T, Egorov A, Seipelt J, Doerr HW and Cinatl J Jr: Oncolytic effects of a novel influenza A virus expressing interleukin-15 from the NS reading frame. PLoS One 7: e36506, 2012

51. Li H, Peng KW, Dingli D, Kratzke RA and Russell SJ: Oncolytic measles viruses encoding interferon beta and the thyroidal sodium iodide symporter gene for mesothelioma virotherapy. Cancer Gene Ther 17: 550-558, 2010.

52. Wang CJ, Xiao CW, You TG, Zheng YX, Gao W, Zhou ZQ, Chen J, Xue XB, Fan J and Zhang H: Interferon- $\alpha$ enhances antitumor activities of oncolytic adenovirus-mediated IL-24 expression in hepatocellular carcinoma. Mol Cancer 11: 31, 2012.

53. Cao L, Zeng Q, Xu C, Shi S, Zhang Z and Sun X: Enhanced antitumor response mediated by the codelivery of paclitaxel and adenoviral vector expressing IL-12. Mol Pharm 10: 1804-1814, 2013.

54. Gollob JA, Mier JW, Veenstra K, McDermott DF, Clancy D, Clancy $M$ and Atkins MB: Phase I trial of twice-weekly intravenous interleukin 12 in patients with metastatic renal cell cancer or malignant melanoma: Ability to maintain IFN-gamma induction is associated with clinical response. Clin Cancer Res 6: 1678-1692, 2000.

55. Lasek W, Zagożdżon $\mathrm{R}$ and Jakobisiak M: Interleukin 12: Still a promising candidate for tumor immunotherapy? Cancer Immunol Immunother 63: 419-435, 2014.
56. Tomura M,Zhou XY, Maruo S, Ahn HJ, Hamaoka T, Okamura H, Nakanishi K, Tanimoto T, Kurimoto M and Fujiwara H: A critical role for IL-18 in the proliferation and activation of NK1.1+ CD3-cells. J Immunol 160: 4738-4746, 1998.

57. Chen C, Fang H, Han Z, Ye F, Ji T, Gong D, Li F, Zhou J, Ma D and Gao Q: Novel permissive murine immunocompetent orthotopic colon carcinoma model for comparison of the antitumoral and safety profiles of three Adv-TKs. Gene Ther 22: 70, 2015

58. Graepler F,Lemken ML, Wybranietz WA, Schmidt U, Smirnow I, Gross CD, Spiegel M, Schenk A, Graf H, Lauer UA, et al: Bifunctional chimeric SuperCD suicide gene-YCD: YUPRT fusion is highly effective in a rat hepatoma model. World $\mathrm{J}$ Gastroenterol 11: 6910-6919, 2005.

59. Lampe J, Bossow S, Weiland T, Smirnow I, Lehmann R, Neubert W, Bitzer M and Lauer UM: An armed oncolytic measles vaccine virus eliminates human hepatoma cells independently of apoptosis. Gene Ther 20: 1033-1041, 2013.

60. Moriuchi S, Wolfe D, Tamura M, Yoshimine T, Miura F, Cohen JB and Glorioso JC: Double suicide gene therapy using a replication defective herpes simplex virus vector reveals reciprocal interference in a malignant glioma model. Gene Ther 9: 584-591, 2002

61. Yamada S, Kuroda T, Fuchs BC, He X, Supko JG, Schmitt A, McGinn CM, Lanuti M and Tanabe KK: Oncolytic herpes simplex virus expressing yeast cytosine deaminase: Relationship between viral replication, transgene expression, prodrug bioactivation. Cancer Gene Ther 19: 160-170, 2012.

62. Redaelli M, Franceschi V, Capocefalo A, D'Avella D, Denaro L, Cavirani S, Mucignat-Caretta C and Donofrio G: Herpes simplex virus type 1 thymidine kinase-armed bovine herpesvirus type 4-based vector displays enhanced oncolytic properties in immunocompetent orthotopic syngenic mouse and rat glioma models. Neuro Oncol 14: 288-301, 2012.

63. Elion GB, Furman PA, Fyfe JA, de Miranda P, Beauchamp L and Schaeffer HJ: Selectivity of action of an antiherpetic agent, 9-(2-hydroxyethoxymethyl) guanine. Proc Natl Acad Sci USA 74: 5716-5720, 1977.

64. Boucher PD, Ostruszka LJ and Shewach DS: Synergistic enhancement of herpes simplex virus thymidine kinase/ganciclovir-mediated cytoxicity by hydroxyurea. Cancer Res 60: 1631-1636, 2000.

65. Freeman SM, Abboud CN, Whartenby KA, Packman $\mathrm{CH}$, Koeplin DS, Moolten FL and Abraham GN: The 'bystander effect': Tumor regression when a fraction of the tumor mass is genetically modified. Cancer Res 53: 5274-5283, 1993.

66. Hong JS, Waud WR, Levasseur DN, Townes TM, Wen H, McPherson SA, Moore BA, Bebok Z, Allan PW, Secrist JA III, et al: Excellent in vivo bystander activity of fludarabine phosphate against human glioma xenografts that express the escherichia coli purine nucleoside phosphorylase gene. Cancer Res 64: 6610-6615, 2004.

67. Leveille S, Samuel S, Goulet ML and Hiscott J: Enhancing VSV oncolytic activity with an improved cytosine deaminase suicide gene strategy. Cancer Gene Ther 18: 435-443, 2011.

68. Folkman J: Tumor angiogenesis: Therapeutic implications. N Engl J Med 285: 1182-1186, 1971.

69. Folkman J: What is the evidence that tumors are angiogenesis dependent? J Natl Cancer Inst 82: 4-6, 1990.

70. Wang Z, Dabrosin C, Yin X, Fuster MM, Arreola A, Rathmell WK, Generali D, Nagaraju GP, El-Rayes B, Ribatti D, et al: Broad targeting of angiogenesis for cancer prevention and therapy. Semin Cancer Biol 35 (Suppl): S224-S243, 2015.

71. O'Reilly MS, Boehm T, Shing Y, Fukai N, Vasios G, Lane WS, Flynn E, Birkhead JR, Olsen BR and Folkman J: Endostatin: An endogenous inhibitor of angiogenesis and tumor growth. Cell 88: 277-285, 1997.

72. O'Reilly MS, Holmgren L, Shing Y, Chen C, Rosenthal RA, Cao Y, Moses M, Lane WS, Sage EH and Folkman J: Angiostatin: A circulating endothelial cell inhibitor that suppresses angiogenesis and tumor growth. Cold Spring Harb Symp Quant Biol 59: 471-482, 1994.

73. Hutzen B, Bid HK, Houghton PJ, Pierson CR, Powell K, Bratasz A, Raffel C and Studebaker AW: Treatment of medulloblastoma with oncolytic measles viruses expressing the angiogenesis inhibitors endostatin and angiostatin. BMC Cancer 14: 206, 2014.

74. Shin SU, Cho HM, Merchan J, Zhang J, Kovacs K, Jing Y, Ramakrishnan S and Rosenblatt JD: Targeted delivery of an antibody-mutant human endostatin fusion protein results in enhanced antitumor efficacy. Mol Cancer Ther 10: 603-614, 2011. 
75. Refaat A, Abd-Rabou A and Reda A: TRAIL combinations: The new 'trail' for cancer therapy (Review). Oncol Lett 7: 1327-1332, 2014.

76. Lichty BD, Breitbach CJ, Stojdl DF and Bell JC: Going viral with cancer immunotherapy. Nat Rev Cancer 14: 559-567, 2014.

77. Hao C, Song JH, Hsi B, Lewis J, Song DK, Petruk KC, Tyrrell DL and Kneteman NM: TRAIL inhibits tumor growth but is nontoxic to human hepatocytes in chimeric mice. Cancer Res 64 : 8502-8506, 2004.

78. Poutou J, Bunuales M, Gonzalez-Aparicio M, Garcia-Aragoncillo E, Quetglas JI, Casado R, Bravo-Perez C, Alzuguren P and Hernandez-Alcoceba R: Safety and antitumor effect of oncolytic and helper-dependent adenoviruses expressing interleukin-12 variants in a hamster pancreatic cancer model Gene Ther 22: 696-706, 2015.

79. El-Shemi AG, Ashshi AM, Na Y, Li Y, Basalamah M, Al-Allaf FA, Oh E, Jung BK and Yun CO: Combined therapy with oncolytic adenoviruses encoding TRAIL and IL-12 genes markedly suppressed human hepatocellular carcinoma both in vitro and in an orthotopic transplanted mouse model. J Exp Clin Cancer Res 35: 74, 2016.
80. Cai Y, Liu X, Huang W and Liu XY: Synergistic antitumor effect of TRAIL and IL-24 with complete eradication of hepatoma in the CTGVT-DG strategy. Acta Biochim Biophys Sin (Shanghai) 44: $535-543,2012$

81. Han Z, Lee S, Je S, Eom CY, Choi HJ, Song JJ and Kim JH Survivin silencing and TRAIL expression using oncolytic adenovirus increase anti-tumorigenic activity in gemcitabine-resistant pancreatic cancer cells. Apoptosis 21: 351-364, 2016

82. Liu X, Cao X, Wei R, Cai Y, Li H, Gui J, Zhong D, Liu XY and Huang K: Gene-viro-therapy targeting liver cancer by a dual-regulated oncolytic adenoviral vector harboring IL-24 and TRAIL. Cancer Gene Ther 19: 49-57, 2012.

83. Gao Y,Zhu Y, Huang X, Ai K, Zheng Q and Yuan Z: Gene therapy targeting hepatocellular carcinoma by a dual-regulated oncolytic adenovirus harboring the focal adhesion kinase shRNA. Int J Oncol 47: 668-678, 2015.

84. Lawler SE, Speranza MC, Cho CF and Chiocca EA: Oncolytic viruses in cancer treatment: A review. JAMA Oncol 3: 841-849, 2017.

85. Warner SG, O'Leary MP and Fong Y: Therapeutic oncolytic viruses: Clinical advances and future directions. Curr Opin Oncol 29: 359-365, 2017. 